\title{
Severe pneumonia in HIV-infected and exposed infants in a paediatric ICU
}

\author{
J Cloete, MB ChB, MMed (Paed), DCH(SA), Dip HIV Man(SA); P Becker, PhD; R Masekela, MB BCh, FC Paed (SA), MMed \\ (Paed), Dip Allergol (SA), Cert Pulm (Paed) (SA), PhD; A Pentz, MB ChB, DCH (SA), FC Paed (SA), MMed (Paed), Dip \\ Allergol (SA), Cert Pulm (Paed) (SA); W Wijnant, FC Paed (SA), MMed (Paed), Dip Allergol (SA), Cert Pulm (Paed) (SA); \\ R de Campos, FC Paed (SA), MMed (Paed), Dip Allergol (SA); O P Kitchin, MB BCh, FC Paed (SA), MMed (Paed), \\ Dip Allergol (SA), Cert Pulm (Paed) (SA); R J Green, PhD, DSc
}

Department of Paediatrics and Child Health, Steve Biko Academic Hospital, Pretoria, South Africa

Corresponding author: J Cloete (jeane.cloete@up.ac.za)

\begin{abstract}
Background. Pneumocystis jiroveci pneumonia is still a common cause of severe disease in HIV-infected infants $<5$ months of age. Despite attention to the prevention of mother-to-child transmission programme in South Africa (SA), HIV testing remains incomplete and infants are still at risk. The management of Pneumocystis pneumonia requires ventilation strategies and combination antibiotics.

Methods. A prospective but open intervention was performed on all HIV-exposed patients admitted with severe pneumonia to the paediatric intensive care unit (PICU) at Steve Biko Academic Hospital, SA, during a 3-year period from January 2009 to December 2011. All patients were treated with ampicillin, amikacin, co-trimoxazole, prednisone and intravenous gancilovir. Highly active antiretroviral therapy (HAART) was initiated in the PICU as soon as tuberculosis was excluded and HIV status confirmed with an HIV viral load (VL). Routine blood and tracheal specimens were cultured for bacteria and tested by direct fluorescent antigen testing for $P$. jiroveci. Cytomegalovirus (CMV) VL was tested. All infants were ventilated in a standard fashion and none were oscillated.

Results. A total of 87 patients were admitted during the 3-year period. Of these, 29 patients were excluded from the study because they were HIV-unexposed. Ten patients died during the 3 -year period. In a multivariate analysis of the presence or absence of $P$. jiroveci, HIV VL, CD4 count, timing of HAART initiation and CMV VL, no single factor was documented to influence mortality.

Conclusion. Mortality from Pneumocystis pneumonia continues to decrease in this PICU. No single factor is responsible and yet all therapeutic strategies contribute to survival. A national policy and guideline is urgently required.
\end{abstract}

S Afr J Child Health 2015;9(3):76-80. DOI:10.7196/SAJCH.7941

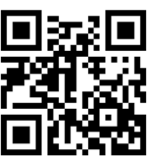

Within South Africa (SA) (as in many other countries), HIV infection is a significant cause of morbidity in women and their infants. In SA, $26 \%$ of pregnant women are HIV-infected, and in the absence of preventive therapy there is a $15-30 \%$ risk of HIV infection in their infants. ${ }^{[1,2]}$ Even children who are part of the prevention of motherto-child transmission (PMTCT) programme have an increased risk of HIV-related infection relative to those who are not exposed, although that risk is substantially reduced. Mortality in HIV-infected children results primarily from respiratory tract infections. ${ }^{[3,4]}$

In children (especially HIV-infected children) with acute severe respiratory disease requiring endotracheal intubation and ventilation, a number of pathogens (including Pneumocystis jiroveci and cytomegalovirus (CMV)) have been isolated. (The term PCP (P. pneumonia) was retained when P. carinii was taxonomically renamed $P$. jiroveci). Although there has been considerable focus on $P$. jiroveci as a cause of mortality, ${ }^{[5]} \mathrm{CMV}$ infection has been reported to affect nearly $90 \%$ of HIV-exposed infants, ${ }^{[6]}$ especially HIVexposed infants with severe pneumonia.

Admitting HIV-infected infants with severe pneumonia to an intensive care unit (ICU) in a resource-limited setting has created a number of ethical dilemmas for paediatricians, which have been accentuated by the historically poor outcome for these patients and the pressure on scarce resources. ${ }^{[7]}$ However, previous reports have suggested that severe pneumonia can now be successfully treated when the mode of ventilation and antibiotic therapy is appropriate for all pathogens that may be present. ${ }^{[8]}$ The successful management of PCP requires careful attention to ventilation strategies, fluid restriction and multiple antibiotics. ${ }^{\left[{ }^{[0}\right.}$

\section{Objective}

To report on the progress in improving survival of HIV-exposed and -infected infants admitted to a PICU with respiratory failure and acute respiratory distress syndrome (ARDS), and to explore the relationship between therapeutic strategies (which have not changed since the previous study $)^{[9]}$ and patient outcomes. In addition, this follow-up study reports on the use of highly active antiretroviral treatment (HAART) initiated in the PICU.

\section{Methods}

All HIV-exposed infants admitted to the PICU at the Steve Biko Academic Hospital in Pretoria, SA, with respiratory failure were recruited into this study. Patients had to fit the diagnosis of ARDS as described by Bernard et al. ${ }^{[8]}$ the most important criterion being hypoxic acute lower respiratory tract infection with a partial pressure of oxygen in mmHg over fraction of inspired oxygen (P/F) ratio of $<200$. Each infant was ventilated using a strategy of high positive end expiratory pressure (PEEP) of $10-15 \mathrm{~cm}$ of water, a tidal volume of $6-8 \mathrm{~mL} / \mathrm{kg}$ and a positive inspiratory pressure (PIP) not exceeding $30 \mathrm{~cm}$ of water. Tidal volume was read from the ventilator display despite limitations of this technique. ${ }^{[10,11]}$ None of the infants was offered high-frequency oscillation ventilation. Total fluid intake was restricted to $60-80 \mathrm{~mL} / \mathrm{kg} /$ day and delivered medication was specifically included in the calculation of total fluid volume.

This prospective study of all consecutive admissions meeting the inclusion criteria was conducted between January 2009 and December 2011. Each child had a number of investigations performed on admission, and airway specimens were collected within 2 hours of endotracheal intubation. Non-bronchoscopic broncho- 
alveolar lavage (NBBAL) specimens were collected for the following: $P$. jirovecii direct fluorescent antigen detection; bacterial microscopy, culture and sensitivity (MC\&S); viral immunofluorescent assay (IFA) testing using the Light Diagnostics kit (Millipore-Chemicon, USA); and tuberculosis (TB) auramine staining and MC\&S (Aerospray Automatic Stainer, Wescor ELiTech Group, France). Blood testing was conducted for white cell count (conducted using the automated haematology analyser Advia 2120, Siemens Diagnostics, SA), C-reactive protein (CRP) (measured using an immunoturbidometric reaction; Beckman Coulter Synchron LX20 PRO, Beckman Coulter Incorporated, USA), and CMV viral load (VL) polymerase chain reaction (PCR) (determined using a Toga lab on Cobas Amplicor instrument, Roche Diagnostics, Switzerland). An HIV DNA PCR was carried out by means of an Amplicor HIV-1 DNA test, version 1.5 (Roche Diagnostics). A peripheral blood volume of $2 \mathrm{~mL}$ was collected for blood culture after careful cleansing of the arm. Blood was immediately injected into relevant blood culture bottles. Blood cultures positive for growth were plated onto agar and sensitivity was measured using a Kirby-Bauer technique (Bactec 9240, Becton Dickinson, USA).

Each infant was treated at presentation with trimethoprimsulphamethoxazole $(20 \mathrm{mg} / \mathrm{kg} /$ day of the trimethoprim component and $100 \mathrm{mg} / \mathrm{kg} / \mathrm{day}$ of the sulphamethoxazole component) and oral steroids $(1-2 \mathrm{mg} / \mathrm{kg} /$ day $)$. Ampicillin and amikacin were routinely added at the time of admission and administered for 5 days unless a resistant organism was cultured, in which case appropriate antibiotics were administered; this is in accordance with the national guideline, which is based on the common organisms cultured in HIV-infected patients presenting with pneumonia. ${ }^{[12]}$ These initial antibacterial antibiotics were changed to meropenem if the patient deteriorated after 48 hours of admission in order to treat the possibility of more resistant hospital-acquired organisms. Trimethoprim-sulphameth-

Table 1. Pathogens isolated from blood culture, non-broncheolar lavage and viral isolates

\begin{tabular}{|c|c|c|c|c|}
\hline Culture & Survivors $(n=43)$ & & Non-survivors $(n=10)$ & \\
\hline \multirow[b]{2}{*}{ Blood } & \multicolumn{2}{|l|}{14 positive blood cultures $(25.4 \%)$} & \multicolumn{2}{|l|}{4 positive blood cultures $(40 \%)$} \\
\hline & Organisms cultured & $n$ & Organisms cultured & $n$ \\
\hline \multirow{9}{*}{$\begin{array}{l}\text { NBBAL, bacterial and } \\
\text { fungal }\end{array}$} & Coagulase-negative Staphylococcus spp. & 6 & Coagulase-negative Staphylococcus spp. & 2 \\
\hline & $\begin{array}{l}\text { Coagulase-negative Staphylococcus spp. and } \\
\text { Enterococcus faecium together }\end{array}$ & 1 & E. faecium & 1 \\
\hline & Streptococcus pneumonia & 1 & S. hominis & 1 \\
\hline & Pseudomonas aeruginosa & 2 & & \\
\hline & Micrococcus spp. & 1 & & \\
\hline & Micrococcus and Bacillus spp. together & 2 & & \\
\hline & Klebsiella pneumoniae & 1 & & \\
\hline & \multicolumn{2}{|l|}{16 positive cultures $(37.2 \%)$} & \multicolumn{2}{|l|}{3 positive cultures $(30 \%)$} \\
\hline & Organisms cultured & $n$ & Organisms cultured & $n$ \\
\hline & Candida parapsylosis only & 1 & C. albicans with ESBL-producing Klebsiella spp. & 1 \\
\hline & C. albicans & 3 & ESBL K. pneumoniae & 1 \\
\hline & Only organism isolated & 2 & K. pneumoniae & 1 \\
\hline & $\begin{array}{l}\text { Multiple organisms with ESBL } K \text {. pneumoniae } \\
\text { and A. baumanii }\end{array}$ & 1 & & \\
\hline & $\begin{array}{l}\text { ESBL } K \text {. pneumoniae (one mixed, one } \\
\text { included) }\end{array}$ & 5 & & \\
\hline & Mycobacterium tuberculosis & 2 & & \\
\hline & K. pneumonia & 3 & & \\
\hline & Cultured mixed with Escherichia coli & 1 & & \\
\hline & E. coli & 2 & & \\
\hline & Mixed with Klebsiella spp. & 1 & & \\
\hline & Streptococcus pneumoniae & 1 & & \\
\hline & 4 positive cultures $(8 \%)$ & & 2 positive cultures $(20 \%)$ & \\
\hline \multirow[t]{3}{*}{ Viral isolates } & Viral pathogens isolated & $n$ & Viral pathogens isolated & $n$ \\
\hline & Parainfluenza 3 (one patient also had TB) & 3 & $\begin{array}{l}\text { Respiratory syncitial virus (patient had C. albicans } \\
\text { with ESBL Klebsiella spp. also isolated on sputum } \\
\text { and negative blood culture) }\end{array}$ & 1 \\
\hline & $\begin{array}{l}\text { Influenza A (patient also had positive } \\
\text { S. pneumoniae blood culture and multiple } \\
\text { organisms cultured on NBBAL) }\end{array}$ & 1 & Adenovirus & 1 \\
\hline
\end{tabular}


oxazole was continued for 21 days and oral steroids for 14 days.

In addition to these therapy standards, all children received intravenous ganciclovir $(10 \mathrm{mg} / \mathrm{kg} /$ day $)$. There are currently no guidelines on what constitutes CMV disease in the setting of CMV viral isolation. For the purposes of this study, CMV infection status was defined as follows: CMV disease: CMV VL >10 000 copies/mL $(\log >4)$; CMV infection: CMV VL $0.1-10000$ copies/mL $(\log -1$ to $\log 4)$ and CMV-uninfected: CMV $\mathrm{VL}$ negative. The value of 10000 copies/mL was extrapolated from previous studies ${ }^{[13-15]}$ and should be used together with clinical, radiological and laboratory support for CMV disease. PCR holds promise as an alternative diagnostic method. ${ }^{[16]}$ Ganciclovir was continued until either CMV VL was $<10000$ copies $/ \mathrm{mL}$ or for 3 weeks after the onset of triple antiretroviral treatment (ART).

Finally, HAART comprising lamuvidine, abacavir and lopinivir/ritonavir combination was initiated in the PICU as soon as TB was excluded and HIV status was confirmed with an HIV VL (RNA replication and amplification RT 2000 (Argos Therapeutics, USA).

Approval to conduct the study was obtained from the Health Sciences Research Ethics Committee of the University of Pretoria and written informed consent was obtained from each parent with the help of a qualified PICU-trained nursing practitioner. In the case of infants who died, permission for postmortem examination was requested from each parent.

\section{Statistical methodology}

The associations of mortality with individual exposure variables, on an ordinal scale, were assessed using Pearson's $\chi^{2}$ test and confirmed using Fisher's exact test; for those exposure variables on a continuous scale, a Student two-sample $t$-test was employed and confirmed using Wilcox's rank sum test. Testing was done at the 0.05 level of significance, and those exposure variables that were significant at the liberal 0.15 level of significance were included into the multivariate logistic regression analysis. Stata 10 (eStataCorp LP, USA) was used for computations.

\section{Results}

A total of 88 infants with pneumonia, respiratory failure and ARDS were admitted during the study period. Four were excluded because data were missing and 29 were excluded because they were HIV-unexposed. Therefore, a total of 55 infants qualified for final analysis (Fig. 1). The mean age was 3.7 (range 2 - 9, median 3) months. None of the infants in this study had received PCP (trimethoprim-sulphamethoxazole) prophy- laxis, but four patients were on HAART at the time of entry to the study. The mean weight for age of the study population was $4.6 \mathrm{~kg}(z$-score $=-2.7)$, which is moderately underweight for age. All study children were HIV-exposed; 53 (96\%) were HIV-infected with a positive HIV DNA PCR, while 2 (4\%) were HIV-uninfected. Ten children (18\%) died. Fifteen (27\%) had $P$. jirovecii identified from an NBBAL specimen. Thirty-five (63\%) children had a positive CMV VL, while 20 (27\% of the total study group) had a CMV VL in the range determined as CMV disease.

The most important outcome in this study was deemed to be survival and therefore discharge from the PICU. Each parameter or laboratory variable that might have reflected an infection on admission was analysed for prediction of mortality. Blood cultures were positive for bacterial organisms in 4 (40\%) and $14(25.4 \%)(p=0.5)$ of non-survivors and survivors, respectively. Other pathogens cultured on blood culture, and NBBAL bacterial, viral and fungal cultures are indicated in Table 1. These bacterial cultures

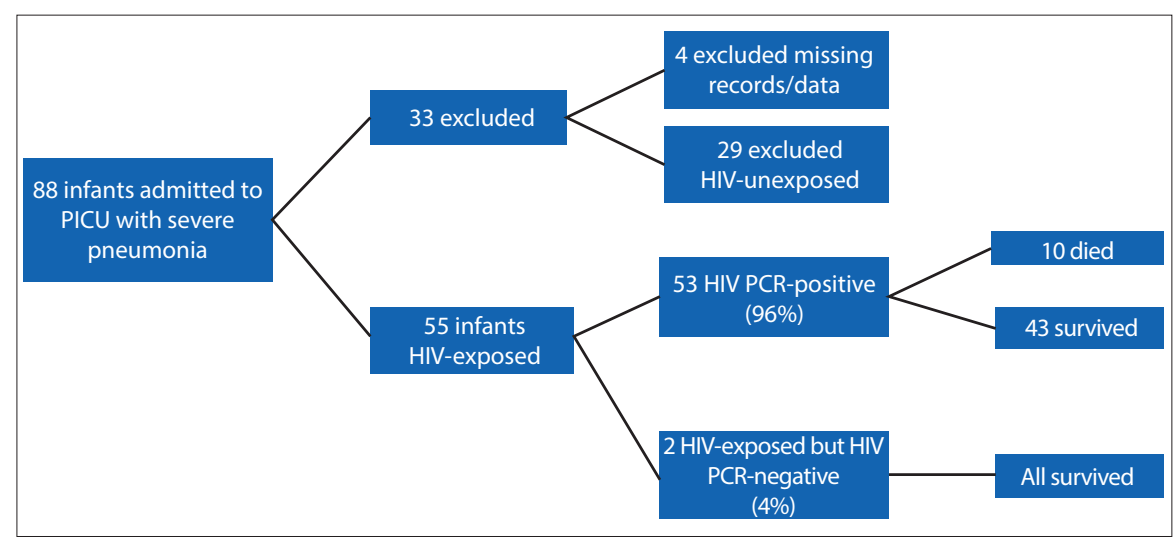

Fig. 1. Inclusion and exclusion criteria.

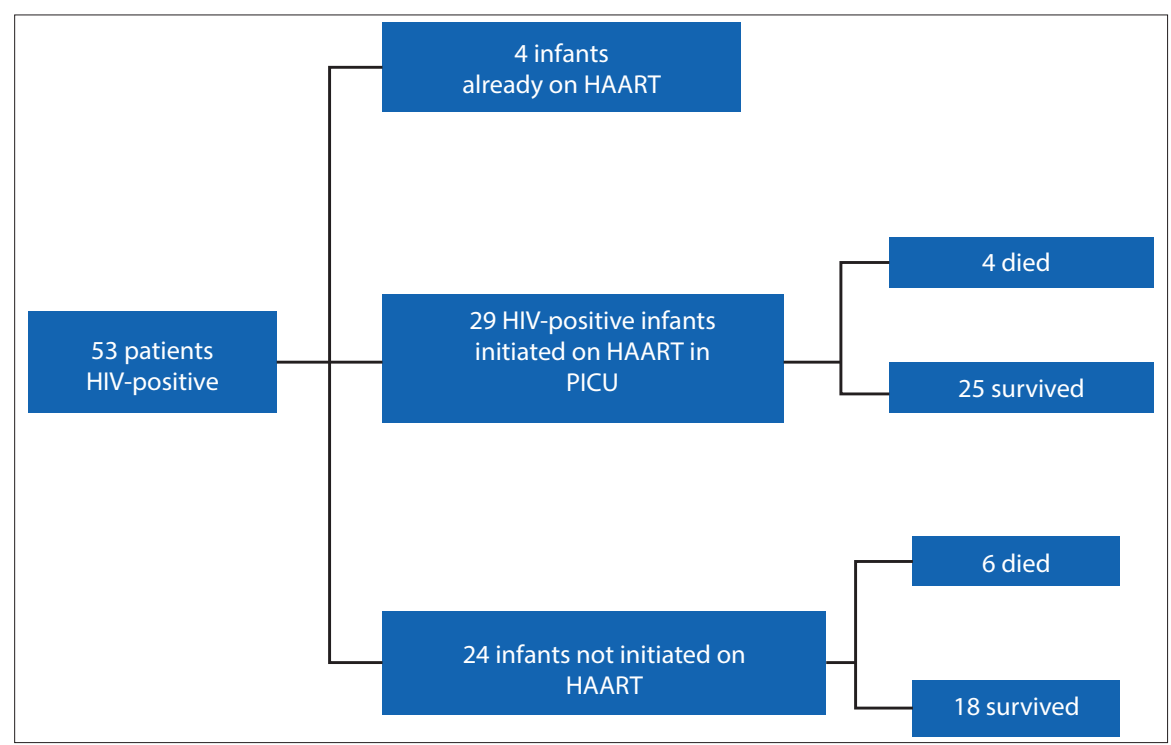

Fig. 2. HAART initiation in infants in PICU. and viral isolates, together with neutropenia (11.1\%) and elevated CRP (15.9\%) were not contributors to mortality ( $p=0.508, p=1.000$, $p=0.256$ and $p=0.685$, respectively).

In a multivariate analysis of the presence or absence of $P$. jirovecii, HIV VL, CD4 count, timing of HIV treatment initiation and CMV VL, no single factor was documented to influence mortality. Included into the multivariate logistic regression, based on a 0.15 level of significance, were CMV status ( $p=0.174), \mathrm{CD} 4$ percentage $(p=0.887)$ and TB identified $(p=0.177)$. Positive identification of $P$. jirovecii per se did not predict mortality $(p=0.419)$. initiation of HAART and survival or death $(p=0.779)$.

Five cases of immune reconstitution with CMV disease and one with TB occurred in the children initiated on HAART while in PICU (Table 2).

\section{Discussion}

Within a setting of HIV disease, mortality from respiratory failure in HIV-infected
There was no relationship between time to 
Table 2. The profile of patients in whom immune reconstitution occurred

\begin{tabular}{|c|c|c|c|c|c|c|c|c|}
\hline $\begin{array}{l}\text { Patient } \\
\text { number }\end{array}$ & $\begin{array}{l}\text { Age } \\
\text { (months) }\end{array}$ & $\begin{array}{l}\text { Death in } \\
\text { PICU }\end{array}$ & $\begin{array}{l}\text { Death in } \\
\text { ward }\end{array}$ & $\begin{array}{l}\text { Days } \\
\text { ventilated }\end{array}$ & PCP IFA & $\begin{array}{l}\text { CMV VL } \\
\text { (log) before } \\
\text { initiation of } \\
\text { HAART }\end{array}$ & $\begin{array}{l}\text { CMV VL } \\
\text { (log) after } \\
\text { initiation } \\
\text { of HAART }\end{array}$ & $\begin{array}{l}\text { TB sputum } \\
\text { culture }\end{array}$ \\
\hline 1 & 7.23 & No & No & 7 & Negative & LDL & 3.63 & Negative \\
\hline 2 & 3.23 & No & No & 10 & Negative & 3.99 & 5.38 & Negative \\
\hline 3 & 1.95 & Yes & No & 22 & Negative & 5.46 & 5.55 & Negative \\
\hline 4 & 2.27 & No & No & 14 & Negative & 5.04 & 5.38 & Negative \\
\hline 5 & 3.12 & No & Yes & 43 & Positive & 3.71 & 5.83 & Negative \\
\hline 6 & 3.62 & No & No & 14 & Positive & 3.72 & LDL & $\begin{array}{l}\text { Positive } \\
\text { (after 1 week) }\end{array}$ \\
\hline
\end{tabular}

and HIV-exposed infants was $18 \%$. This is lower than in the study reported for the preceding 2-year period. ${ }^{[9]}$ This is believed to be a result of the continued attention to management strategies in these infants. The only additional management tool that was added in subsequent years was early introduction of HAART in the PICU. This addition would probably add benefit to survival, but this study was not able to explore that effect as all children received it. However, because of logistical issues, not all children received their HAART at the same time during their stay. Analysis of the timing of onset of this therapy, however, did not reveal significant benefit between early and late initiation. If it is considered that mortality often occurs early, this may lead to the conclusion that HAART does not confer benefit. It certainly, however, does not impair survival.

Unlike the previous study from this centre, ${ }^{[9]}$ no specific factor was now shown to be associated with mortality. Two reasons for this phenomenon are proposed: firstly, overall mortality is now so low that the number of patients in identified risk groups is small; secondly it seems likely that the overall management plan, with all the selected interventions, is now contributing, in unison, to survival. The survival disadvantage from CMV disease identified in the previous study ${ }^{[9]}$ is now lost. This is encouraging, as this centre has persevered with the use of early ganciclovir despite initial suggestions of failure of this form of therapy to halt mortality ${ }^{[8]}$ The important lesson in PCP, a severe and often fatal condition, is that the results of a single study should not be used to make life-saving or life-ending decisions.

In addition to documentation of improved survival from PCP, it should be noted that the mode of ventilation had not changed in this PICU. No infant received ventilation by means of high-frequency oscillation (HFO). This is an important feature of this study, since it has been suggested that PCP with ARDS requires HFO. Survival despite the absence of this strategy has cost implications for a developing country and should be factored into national policy.

Until such time as identification, prevention and prophylaxis of HIV in pregnancy is secure in the developing world, it seems prudent to develop a national or international guideline and policy on management of this condition. Currently, pneumonia guidelines are quiet on this issue.

A case fatality rate of $18 \%$ has been achieved through a meticulous approach to management of the interaction between the host and infection in infants with respiratory failure. This has been demonstrated previously. ${ }^{[9]}$ In 2004, Cooper et al. ${ }^{[17]}$ documented that HIV-infected children admitted to a PICU in London had a $38 \%$ mortality when every effort was made to treat such children. The actual mortality of these infants beyond the PICU into the first year of life is a subject of an ongoing study. However, all the patients in the Cooper et al. ${ }^{[17]}$ study who were HIV-infected received ART early in the course of their disease, and survival to 1 year of age appears to be better than reported in previous studies. ${ }^{[18]}$

It appears that in exchange for improved survival, the use of HAART may be unmasking immune reconstitution inflammatory syndrome with emergence of infectious diseases. However, those conditions are treatable and children survive them.

\section{Study limitations}

The major limitation of our study was the definition of CMV disease. Clearly, use of a blood measure of VL does not imply pulmonary disease. This fact has not escaped our attention, but, short of lung biopsy, actual proof of CMV infection has been difficult in previous studies. In addition, the close correlation between CMV VL and mortality must suggest that this test is identifying some disease process. Exactly what that disease is, is unclear from our study. Some additional limitations include failure to identify fully all potential pathogens through PCR and culture techniques. Such testing would enhance the diagnostic yield in our study, but would, of course, not have changed our therapeutic strategy as all organisms, with the exception of TB, were empirically treated. An attempt was also made to get postmortem biopsies on the 10 deaths, but permission was denied by all the parents. This would have given us the opportunity to observe the histology of the lungs in order to determine whether fibrosis was the end-stage pathology of patients with this form of ARDS.

\section{Conclusion}

Respiratory failure in infants who are HIV-exposed or -infected has more than one aetiology, and mortality can be improved through multiple treatment modalities. Perseverance with ventilation and multiple antibiotic agents is highly successful for curing a previously fatal respiratory disease. The value of early HAART is difficult to assess but may be contributing to improved survival. At the very least it is not detrimental.

It remains pertinent to point out that effective antenatal care with diagnosis and appropriate therapy of infected mothers can virtually eliminate the secondary problems of HIV infection in young children.

\section{References}

1. National Department of Health South Africa Policy and Guidelines of Implementing PMTCT Programme. 2008 http://www.doh.gov.za/docs/ policy-f.htmL (accessed 1 April 2011).

2. De Cock KM, Fowler MG, Mercier E, et al. Prevention of mother-to-child HIV transmission in resource-poor countries: Translating research into policy and practice. JAMA 2000;283(9):1175-1182.

3. Graham SM, Gibb DM. HIV disease and respiratory tract infection in children. Br Med Bull 2002;61:133-150. 
4. Jeena P. The role of HIV on respiratory tract infection in sub-Saharan Africa. Int Tuberc Lung Dis 2005;9(7):708-715.

5. Stringer JR, Beard CB, Miller RF, Wakefield AE. A new name (Pneumocystis jiroveci) for pneumocystis from humans. Emerg Infect Dis 2002;8(9):891-896. [http://dx.doi.org/10.3201/eid0809.020096]

6. Slyker JA, Lohman-Payne BL, John-Stewart GC, et al. Acute cytomegalovirus infection in Kenyan HIV-infected infants. AIDS 2009;23(16):2173-2181. [http://dx.doi.org/10.1097/QAD.0b013e32833016e8]

7. Jeena MP, McNally LM, Stobie M, Coovadia HM, Adhikari MA, Petros AJ. Challenges in the provision of ICU services to HIV infected children in resource poor settings: A South African case study. J Med Ethics 2005;31(4):226-230. [http://dx.doi.org/10.1136/jme.2003.004010]

8. Bernard GR, Artiqas A, Brigham AL, et al. Report of the American-European consensus conference on ARDS: Definitions, mechanisms, relevant outcomes and clinical trial coordination. The Consensus Committee. Inten Care Med 1994;20(3):225-232.

9. Kitchin O, Masekela R, Moodley T, et al. Outcome of HIV exposed and infected children admitted to a pediatric intensive care unit for respiratory failure. Pediatr Crit Care Med 2012;13(5):516-519. [http://dx.doi.org/10.1097/PCC.0b013e31824ea143]

10. Heulitt MJ, Thurman TL, Holt SJ, et al. Reliability of displayed tidal volume in infants and children during dual-controlled ventilation. Pediatr Crit Care Med 2009;10(6):661-667. [http://dx.doi.org/ 10.1097/PCC.0b013e3181bb2b2b]

11. Castle RA, Dunne CJ, Mok Q, et al. Accuracy of displayed values of tidal volume in the pediatric intensive care unit. Crit Care Med 2002;30(11):25662574. [http://dx.doi.org/10.1097/01.CCM.0000034675.10801.2A]
12. Zar HJ, Jeena P, Argent A, et al. Diagnosis and management of communityacquired pneumonia in childhood: South African Thoracic Society Guidelines. S Afr Med J 2005;95(12 pt 2):977-990

13. Boeckh M, Boivin G. Quantitation of cytomegalovirus: Methodologic aspects and clinical applications. Clin Microbial Rev 1998;11(3):533-554.

14. Hsiao NY, Zampoli M, Morrow B, Zar HJ, Hardie D. Cytomegalovirus viraemia in HIV exposed and infected infants: Prevalence and clinical utility for diagnosing CMV pneumonia. J Clin Virol 2013;58(1):74-78. [http://dx.doi.org/10.1016/j. jcv.2013.05.002]

15. Zampoli M, Morrow B, Hsiao M, Whitelaw A, Zar HJ. Prevalence and outcome of cytomegalovirus-associated pneumonia in relation to human immunodeficiency virus. Pediatr Infect Dis J 2011;30(5):413-417. [http:// dx.doi.org/10.1097/INF.0b013e3182065197]

16. Bransaeter AB, Holberg-Petersen $M$, Jeansson S, et al. CMV quantitaitive PCR in the diagnosis of CMV disease in patients with HIV-infection: A retrospective autopsy based study. BMC Infect Dis 2007;7:127-134. [http:// dx.doi.org/10.1186/1471-2334-7-127]

17. Cooper S, Lyall H, Walters S, et al. Children with human immunodeficiency virus admitted to a paediatric intensive care unit in the United Kingdom over a 10-year period. Intensive Care Med 2004;30(1):113-118. [http://dx.doi. org/10.1007/s00134-003-2074-7]

18. Cowburn C, Hatherill M, Eley B, et al. Short-term mortality and implementation of antiretroviral treatment for critically ill HIV-infected children in a developing country. Arch Dis Child 2007;92(3):234-241. [http:// dx.doi.org/10.1136/adc.2005.074856] 